\title{
Carbon-nitrogen/graphene composite as metal-free electrocatalyst for the oxygen reduction reaction
}

\author{
MA YanWen ${ }^{1}$, ZHANG LingRong ${ }^{1}$, LI JuanJuan ${ }^{1}$, NI HaiTao ${ }^{1}$, LI Meng ${ }^{1}$, ZHANG JinLei ${ }^{1}$, \\ FENG XiaoMiao ${ }^{1}$, FAN QuLi $^{1}, \mathrm{HU}^{2}$ Zheng $^{2} \&$ HUANG Wei ${ }^{1{ }^{1}}$ \\ ${ }^{1}$ Jiangsu Key Laboratory for Organic Electronics \& Information Displays and Institute of Advanced Materials, Nanjing University of Posts and \\ Telecommunications, Nanjing 210046, China; \\ ${ }^{2}$ Key Laboratory of Mesoscopic Chemistry of Ministry of Education, Jiangsu Provincial Laboratory for Nanotechnology, School of \\ Chemistry and Chemical Engineering, Nanjing University, Nanjing 210093, China
}

Received January 27, 2011; accepted March 21, 2011

\begin{abstract}
Sheet-like carbon-nitrogen $\left(\mathrm{CN}_{x}\right)$ /graphene composites with a high content of nitrogen $(x \leqslant 0.15)$ was prepared by the carbonization of polypyrrole (PPy)/reduced-graphene-oxide (rGO) composite at $600-800^{\circ} \mathrm{C}$. We used rGO instead of graphene oxide (GO) sheets as a template and a substrate to immobilize PPy since the PPy/GO composite agglomerates easily because of the dehydration of excess oxygen-containing groups on the GO sheets during the drying process. The dried PPy/rGO intermediate and its derived $\mathrm{CN}_{x} /$ graphene products retain their high dispersion and loose-powder features. The as-prepared $\mathrm{CN}_{x} /$ graphene composites have a total nitrogen content of about 10 at $\%$ and their nitrogen state is mainly of pyridinic and graphitic type. $\mathrm{CN}_{x} / \mathrm{graphene}$ composites exhibit excellent performance for the oxygen reduction reaction (ORR) in terms of electrocatalytic activity, stability and immunity towards methanol crossover and CO poisoning, suggesting their potential as metal-free electrocatalysts for the ORR.
\end{abstract}

graphene, graphene oxide, carbon nitride, metal-free electrocatalyst, oxygen reduction reaction

Citation: Ma Y W, Zhang L R, Li J J, et al. Carbon-nitrogen/graphene composite as metal-free electrocatalyst for the oxygen reduction reaction. Chinese Sci Bull, 2011, 56: 3583-3589, doi: 10.1007/s11434-011-4730-6

Low temperature fuel cells are a high-efficiency and environment-friendly energy supply for future transport and portable applications [1,2]. However, despite the great efforts worldwide over the past few decades their wide application in daily life is still a challenge because of the scare resources, high cost and durability issues for the current commercial $\mathrm{Pt} / \mathrm{C}$ catalysts, especially for cathodes where the oxygen reduction reaction (ORR) is kinetically slow [3-5]. Therefore, research into non-precious metals or even metal-free catalysts with high ORR activity and durability is absolutely crucial for the development of fuel cells.

Currently, it is widely accepted that nitrogen-containing carbon including macrocycle molecules [6-8], polymers [4,9] and nanomaterials [10-19] are a type of important building block for the preparation of Pt-substituted catalysts.

*Corresponding author (email: iamwhuang@njupt.edu.cn)
Iron- or cobalt-doped carbon-nitrogen $\left(\mathrm{CN}_{x}\right)$ compounds have comparable activity to $\mathrm{Pt} / \mathrm{C}$ catalysts in acidic systems $[4,7,9,20]$. Polypyrrole modified carbon-supported cobalt hydroxide can act as cathode and anode catalysts in direct borohydride fuel cells [21,22]. Recent promising results involving metal-free PEDOT [5] and nitrogen-doped carbon nanotubes (NCNTs) [14-19] have been reported for alkaline systems giving excellent electrocatalytic activity, stability and immunity towards methanol crossover and $\mathrm{CO}$ poisoning. Particularly, NCNTs have attracted extensive interest because of their large surface area, good thermal and chemical stability as well as high electrical conductivity [14-19]. It has been revealed that increasing the nitrogen content and the number of defects in NCNT enhances its electrocatalytic activity toward the ORR $[11,16]$. In addition to one-dimensional CNTs, the emergence of graphene has opened up a new field in terms of research into two-dimensional (2D) 
metal-free electrocatalysts [23-29]. Graphene has many similar properties to CNTs and its 2D planar sheet is beneficial for electron transport and, therefore, it is an ideal electrode material $[23,24]$. Nitrogen doped graphene with a low nitrogen concentration of 2 at $\%-5$ at $\%$ can be synthesized by chemical vapor deposition [25,30] or by the postnitridization of graphene oxide [28,31]. To increase the nitrogen content, researchers have immobilized a nitrogencontaining polymer such as polyaniline [32] or polymelamine onto the graphene oxide (GO) surface to form polymer/ GO composite [29], which can be converted to $\mathrm{CN}_{x}$ /graphene composite by carbonization to catalyze the ORR. The main challenge for the preparation of the intermediate of the polymer/GO-composite powder is to avoid agglomeration and caking after natural drying because of GO sheet dehydration [32]. Therefore, it is necessary to eliminate the excess oxygen-containing groups on the GO sheets by the reduction method while retaining the high dispersion of reduced GO (rGO) in solution. In this study, we prepared highly dispersed rGO solution by hydrothermal reduction and then polypyrrole (PPy) was added onto the rGO sheets to prepare the PPy/rGO composite. Finally, the fabricated $\mathrm{CN}_{x}$ /graphene composite with a nitrogen content of about 10 at $\%$ was prepared by simple carbonization. The obtained $\mathrm{CN}_{x} /$ graphene composite is shown to be a metal-free electrocatalyst for the ORR with good electrocatalytic activity, longterm operation stability and a high tolerance of the crossover effect, indicating their potential use in alkaline fuel cells.

\section{Experimental}

\subsection{Synthesis of graphite oxide}

Graphite oxide was synthesized by the modified Hummers method [33]. In short, 1 g natural graphite (325 mesh, Alfa Aesar) was added to $50 \mathrm{~mL}$ concentrated sulfuric acid while stirring in an ice-water bath. Then, $6 \mathrm{~g}$ potassium permanganate was added slowly and the mixture was stirred at $30^{\circ} \mathrm{C}$ for $1 \mathrm{~h}$ after which $80 \mathrm{~mL}$ distilled water was added and the mixture was further stirred for $30 \mathrm{~min}$ and the temperature was increased to $90^{\circ} \mathrm{C}$. Finally, $200 \mathrm{~mL}$ distilled water and $6 \mathrm{~mL} \mathrm{H}_{2} \mathrm{O}_{2}(30 \%)$ were added dropwise and the solution changed color from dark brown to yellow. The generated solid graphite oxide was separated by centrifugation, washed and finally dried under vacuum.

\subsection{Preparation of the PPy/rGO composite}

Graphite oxide (40 mg) was dispersed in $40 \mathrm{~mL}$ deionized water by sonication to form a $1 \mathrm{mg} / \mathrm{mL}$ GO suspension, which was transferred into $50 \mathrm{~mL}$ autoclaves and heated at $150^{\circ} \mathrm{C}$ for $12 \mathrm{~h}$. After the reduction, a black homogeneous rGO suspension was obtained. Pyrrole monomer $(0.05 \mathrm{~mL})$ was added into the rGO solution and magnetically stirred for $24 \mathrm{~h}$ at room temperature. Then, $50 \mathrm{~mL}$ of an aqueous solution containing $189.5 \mathrm{mg}$ ammonium peroxydisulfate was added as an oxidizing agent to initiate the polymerization for $24 \mathrm{~h}$ in an ice-bath. After the reaction, the solid sample was filtered and thoroughly washed with deionized water and ethanol alternately, and then it was dried naturally to form a PPy/rGO powder. For comparison, the PPy/GO composite was also prepared by the direct use of GO as a substrate without hydrothermal treatment.

\subsection{Preparation of the $\mathrm{CN}_{x}$ /graphene composite}

PPy/rGO powder $(0.1 \mathrm{~g})$ was placed in a quartz tube furnace and heated under Ar from room temperature to 600 and $800^{\circ} \mathrm{C}$ at a rate of $1^{\circ} \mathrm{C} / \mathrm{min}$ and kept there for $2 \mathrm{~h}$. A black powder was obtained after the furnace was cooled to room temperature and this was denoted $\mathrm{CN}_{x} / \mathrm{G}-600$ or $\mathrm{CN}_{x} / \mathrm{G}-800$, respectively, according to the annealing temperature.

\subsection{Characterization}

The products were characterized by transmission electron microscopy (TEM, JEOL-JEM-1005 at $100 \mathrm{kV}$ ), scanning electron microscopy (SEM, Hitachi S-4800), high-resolution transmission electron microscopy (HRTEM, JEM2010 at $200 \mathrm{kV}$ ), Fourier transform infrared spectroscopy (FTIR, BRUKERVECTOR22) with $\mathrm{KBr}$ pressed pellets, Raman spectroscopy (Renishaw in Via Raman Microscope with an argon-ion laser at an excitation wavelength of $514 \mathrm{~nm}$ ) and X-ray photoelectron spectroscopy (XPS, VG ESCALAB MKII).

Electrochemical measurements included rotating disk electrode (RDE) and rotating ring-disk electrode (RRDE) voltammetries were carried out at $25^{\circ} \mathrm{C}$ on a $\mathrm{CHI} 760 \mathrm{C}$ workstation ( $\mathrm{CH}$ Instruments). $\mathrm{Ag} / \mathrm{AgCl}$ and a platinum wire served as reference and counter electrodes, respectively. The RDE and RRDE voltammetry experiments were performed on a MSR electrode rotator (Pine Instrument Co.). RDE voltammetry was conducted using a glassy carbon (GC) electrode (5 $\mathrm{mm}$ diameter) while for RRDE voltammetry we used a GC disk electrode ( $5 \mathrm{~mm}$ diameter) surrounded by a $\mathrm{Pt}$ ring $(6.5 \mathrm{~mm}$ inside diameter). The GC electrode was modified as following: A suspension of catalyst with a concentration of $1.0 \mathrm{mg} \mathrm{mL}^{-1}$ was made by ultrasonically dispersing $1 \mathrm{mg}$ catalyst in $1 \mathrm{~mL}$ water. Then, $100 \mu \mathrm{L}$ of the catalyst suspension was dropped onto a glassy carbon disk (GC) intermittently. 0.5 $\mathrm{L}$ Nafion (Dupont, $5 \mathrm{wt} \%$ ) was then coated onto the surface of the thin film electrode and dried thoroughly in air for $12 \mathrm{~h}$. ORR evaluation was performed in a $0.1 \mathrm{~mol} \mathrm{~L}^{-1} \mathrm{KOH}$ electrolyte that was saturated and protected by $\mathrm{O}_{2}$. The electrochemical performances of all the catalysts were examined determined in a $0.1 \mathrm{~mol} / \mathrm{L} \mathrm{KOH}$ solution.

Thin film electrodes for each catalyst were prepared for the methanol crossover and $\mathrm{CO}$ poisoning tests by the same procedure. Simply, $20 \mu \mathrm{L}$ of the catalyst suspension was 
dropped onto a glassy carbon disk. After drying thoroughly, $0.5 \mu \mathrm{L}$ Nafion (Dupont, $5 \mathrm{wt} \%$ ) was coated onto the surface of the thin film electrode. Methanol crossover and $\mathrm{CO}$ poisoning were studied at a polarizing potential of $-0.3 \mathrm{~V}$ through their $i$ - $t$ chronoamperometric response in the oxygen saturated electrolyte by bubbling $\mathrm{O}_{2}$ into the electrolyte at a flowrate of $30 \mathrm{sccm}$ (standard cubic cemtimeter perminute). During this process, $0.1 \mathrm{~mL}$ methanol or a $30 \mathrm{sccm}$ (standard cubic cemtimeter perminute) flow of $\mathrm{CO}$ was introduced into the electrolyte over $400 \mathrm{~s}$ to examine methanol crossover and $\mathrm{CO}$ poisoning.

\section{Results and discussion}

Before using rGO as a substrate to immobilize PPy, we prepared a PPy/GO composite with a weight ratio of $1: 1$ and observed that the dried powder agglomerated into particles and could not be redispersed into water after $30 \mathrm{~min}$ of ultrasonication (Figure 1(a)). The composite "cake" was a result of dehydration among the unenclosed GO sheets during the drying process. To avoid this agglomeration, hydrothermally treated $\mathrm{GO}$, i.e., rGO, instead of pristine $\mathrm{GO}$ was used as a matrix to support the polymer. According to our previous study [34], the $\mathrm{C} / \mathrm{O}$ atomic ratio for $\mathrm{GO}$ is $\sim 3.4$ while that for $\mathrm{rGO}$ is $\sim 7.6$. Reduced GO sheets with less oxygen containing groups can also maintain high dispersion in solution in the form of free-standing flakes, as shown in Figure 1(b). Obviously, the dry PPy/rGO composite is much looser than PPy/GO and the former can easily form a homogeneous dispersion after several minutes of ultrasonication (Figure 1(a)). As shown by a typical TEM image of $\mathrm{PPy} / \mathrm{rGO}$ (Figure 1(c)), the PPy polymer attaches tightly to the rGO sheet and forms a thicker plate than the pristine rGO sheet. After calcination, the samples retained their plate-like morphology. The HRTEM image of the calcinated sample shows the microstructure at the edge where the stacking structure is distinguishable and the discontinuous graphitic layers indicate the formation of graphite fragments. The EDS spectrum reveals $\mathrm{N}$ doping with an uncalibrated content of 5.7 at $\%$, which indicates the formation of the $\mathrm{CN}_{x} /$ graphene composite.

SEM images of $\mathrm{rGO}$ and $\mathrm{CN}_{x} / \mathrm{G}-800$ are shown in Figure 2. The image for rGO shows that the thin and wrinkled sheets are stacked tightly together. Compared with $\mathrm{rGO}$, the $\mathrm{CN}_{x} / \mathrm{G}-800$ sheets looks much thicker and they are also stacked as composite flakes, as shown in the insert in Figure 2(b). This slight aggregation of the $\mathrm{CN}_{x}$ /graphene composite does not affect their dispersion in solution and a homogeneous suspension with high stability can be obtained for the preparation of a thin film electrode.

The functional groups on the surface of the rGO, PPy/

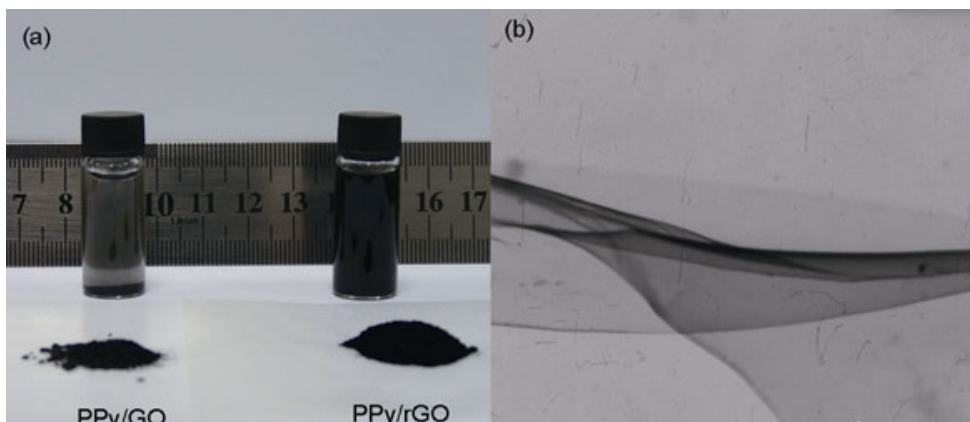

$\mathrm{PPy} / \mathrm{GO}$

PPy/rGO

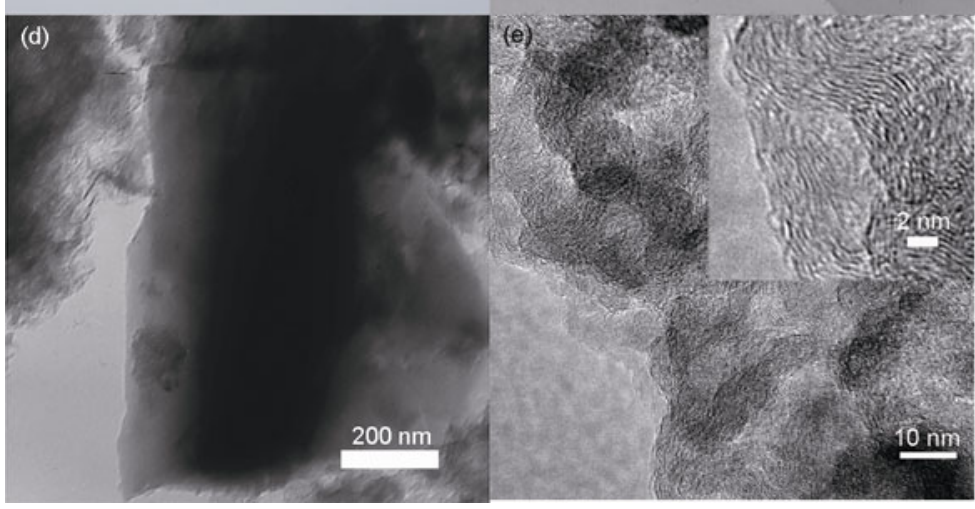

(c)
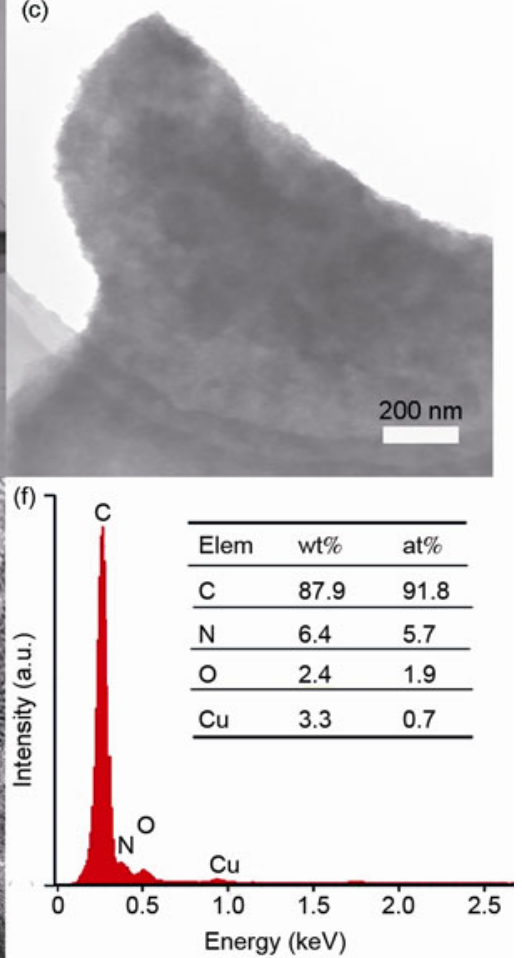

Figure 1 (a) Photographs of the PPy/GO and PPy/rGO composite powders and their solutions. PPy/GO was not well dispersed in the solution after 30 min of ultrasonication while PPy/rGO tends to form a homogeneous dispersion after several minutes of ultrasonication; typical TEM images of rGO sheets (b), PPy/rGO (c) and $\mathrm{CN}_{x} / \mathrm{G}-800$ (d); (e) HRTEM image of $\mathrm{CN}_{x} / \mathrm{G}-800$. The insert is an enlarged image; (f) EDS spectrum and the derived elemental composition of $\mathrm{CN}_{x} / \mathrm{G}-800$. 

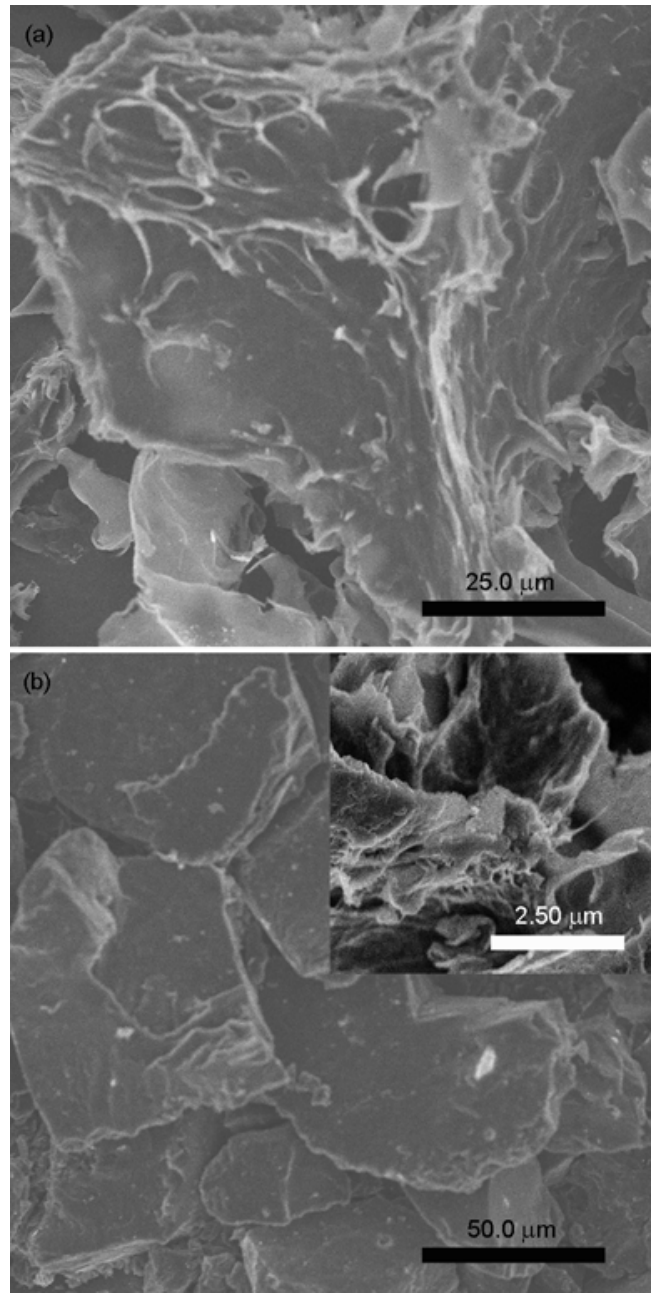

Figure 2 SEM images of rGO (a) and $\mathrm{CN}_{x} / \mathrm{G}-800$ (b). The insert in (b) is a local enlargement.

rGO and $\mathrm{CN}_{x} /$ graphene composites were analyzed by FTIR (Figure 3(a)). The spectrum of rGO gives typical peaks at $1060 \mathrm{~cm}^{-1}$ for the $\mathrm{C}-\mathrm{O}$ stretching vibration and $1714 \mathrm{~cm}^{-1}$ for $\mathrm{C}=\mathrm{O}$ [35]. The pyrrole ring vibration at 1456 and $1560 \mathrm{~cm}^{-1}$ accompanied by the $=\mathrm{C}-\mathrm{H}$ in-plane deformation at 1180 and $1336 \mathrm{~cm}^{-1}$ appear in the FTIR spectrum of the PPy/rGO composite [36]. After annealing at 600 and $800^{\circ} \mathrm{C}$, the characteristic peaks for PPy diminish while some peaks between $1100-1700 \mathrm{~cm}^{-1}$ come from $\mathrm{C}-\mathrm{N}$ and $\mathrm{C}=\mathrm{N}$ stretching vibrations [37]. Figure 3(b) shows Raman spectra of rGO, PPy/rGO and their derived carbon nitride composites. All the samples have spectra with two peaks centered at $\sim 1353 \mathrm{~cm}^{-1}$ (D-band) and $\sim 1594 \mathrm{~cm}^{-1}$ (G-band) [38]. The G-band is assigned to one of the two $E_{2 \mathrm{~g}}$ modes corresponding to stretching vibrations in the basal-plane $\left(s p^{2}\right.$ domains) of single crystal graphite or graphene. The D-band is usually attributed to disorders and imperfections in carbon crystallites. The intensity ratio of the D-band to G-band $\left(I_{\mathrm{D}} / I_{\mathrm{G}}\right)$ in the Raman spectrum should approximately correspond to the extent of disorder in the graphitic carbon [26,38].
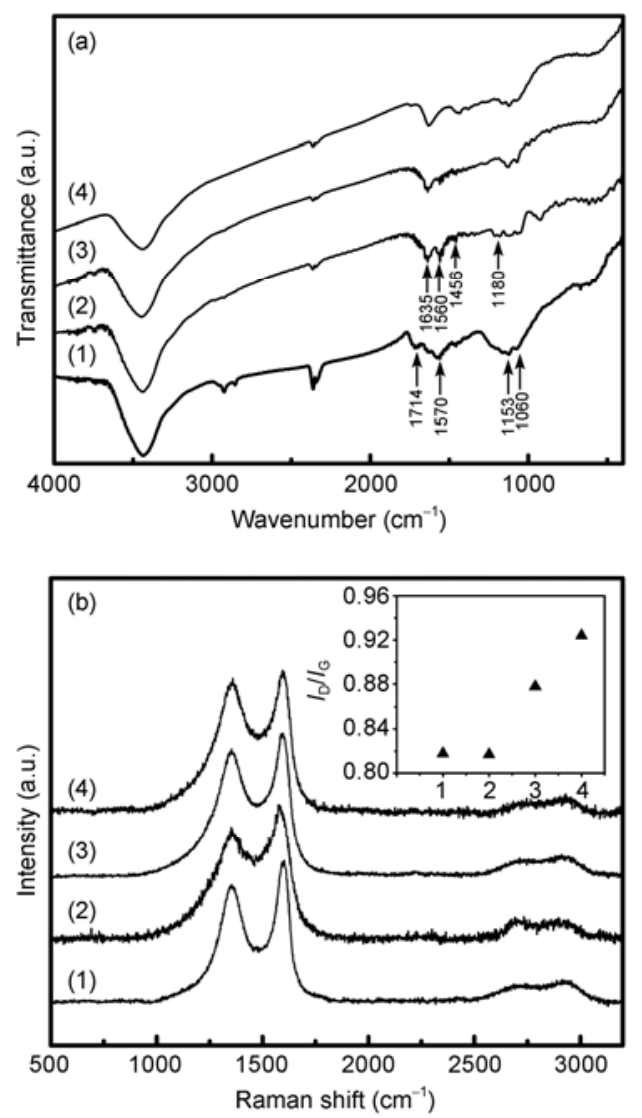

Figure 3 FTIR (a) and Raman spectra (b) of rGO (1), PPy/rGO (2), $\mathrm{CN}_{x} / \mathrm{G}-600$ (3) and $\mathrm{CN}_{x} / \mathrm{G}-800$ (4). The insert in (b) is the $I_{\mathrm{D}} / I_{\mathrm{G}}$ ratio profile for each sample.

The $I_{\mathrm{D}} / I_{\mathrm{G}}$ ratio of $\mathrm{CN}_{x} /$ graphene is higher than that of $\mathrm{rGO}$ indicating that $\mathrm{CN}_{x} /$ graphene has a higher distortion.

The chemical state evolution of nitrogen before and after calcination was analyzed by XPS as shown in Figure 4. From the XPS survey scan in Figure 4(a), the spectrum of rGO does not have a $\mathrm{N}$ signal as expected. The relative intensities of the $\mathrm{N} 1 \mathrm{~s}$ and $\mathrm{O} 1 \mathrm{~s}$ peaks for $\mathrm{PPy} / \mathrm{rGO}, \mathrm{CN}_{x} / \mathrm{G}-600$ and $\mathrm{CN}_{\mathrm{x}} / \mathrm{G}-800$ decrease sequentially because of the higher annealing temperature. The $\mathrm{N} 1 \mathrm{~s}$ spectrum for $\mathrm{PPy} / \mathrm{rGO}$, $\mathrm{CN}_{x} / \mathrm{G}-600$ and $\mathrm{CN}_{x} / \mathrm{G}-800$ can be fitted to individual component peaks that represent pyrrolic $\mathrm{N}$ at a binding energy (Eb) of $399.8 \mathrm{eV}$, pyridinic $\mathrm{N}$ at a $\mathrm{Eb}$ of $398.3 \mathrm{eV}$ and graphitic $\mathrm{N}$ at a Eb between 400.9-401.1 eV [26,27,31]. Additionally, the N1s spectra of the carbonized sample (Figure 4(c) and (d)) also contain two other peaks at Ebs of 403.2 and $405.0 \mathrm{eV}$, corresponding to $\mathrm{N}$-oxide and intercalated $\mathrm{N}_{2}$, respectively [39]. The total $\mathrm{N}$ content obtained from XPS as well as the pyrrolic, pyridinic and graphitic nitrogen content from the relative peak intensities depends on the annealing temperature, as plotted in Figure 4(e). For the as-prepared $\mathrm{PPy} / \mathrm{rGO}$ composite at room temperature, approximately $90 \%$ of the nitrogen exists as pyrrolic $\mathrm{N}$ and the total $\mathrm{N}$ content is about 14 at $\%$. With an increase in the annealing temperature, the total $\mathrm{N}$ and pyrrolic $\mathrm{N}$ decreases while the 

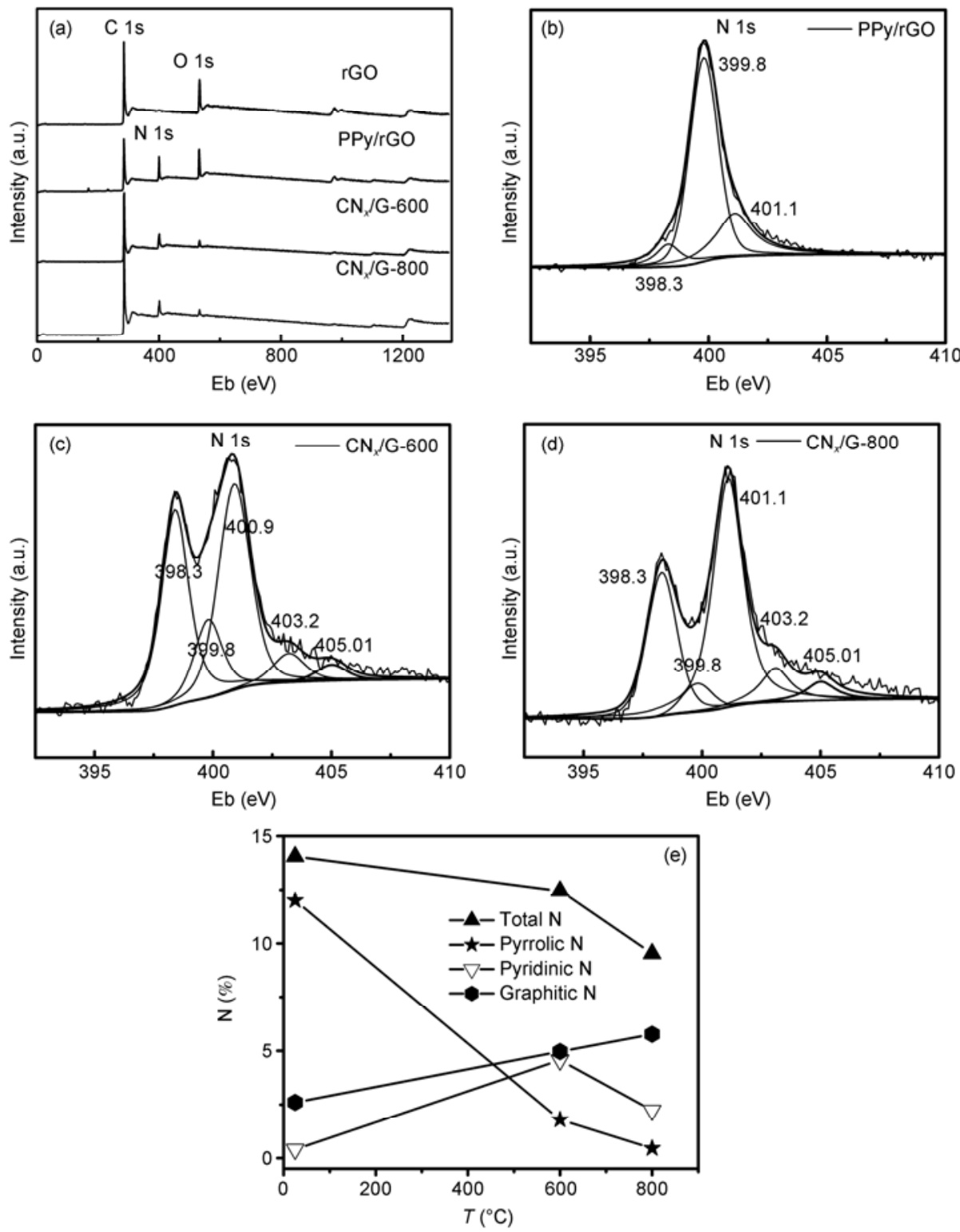

Figure 4 XPS spectra of rGO, PPy/rGO, CN $/$ G-600 and $\mathrm{CN}_{x} / \mathrm{G}-800$. Survey scan (a); N1s narrow scan of PPy/rGO (b), CN $\mathrm{N}_{x} / \mathrm{G}-600$ (c) and CN $\mathrm{CN}_{x} / \mathrm{G}-800$ (d); (e) the total $\mathrm{N}$ content, the derived pyrrolic $\mathrm{N}$, the pyridinic $\mathrm{N}$ and the graphitic $\mathrm{N}$ vs. the annealing temperature.

graphitic $\mathrm{N}$ increases. The pyridinic $\mathrm{N}$ reaches its highest content at $600^{\circ} \mathrm{C}$. The total $\mathrm{N}$ content for $\mathrm{CN}_{x} / \mathrm{G}-600$ and $\mathrm{CN}_{x} / \mathrm{G}-800$ are 12.5 at $\%$ and 9.8 at $\%$, respectively.

The electrocatalytic activities of the $\mathrm{CN}_{x} /$ graphene composites were determined using RDE and RRDE voltammetries (Figure 5). For RDE (Figure 5(a)) the onset potential of oxygen reduction for the $\mathrm{CN}_{x}$ /graphene composites are about $-1.9 \mathrm{~V}$, which is much higher than that of the PPy/ rGO composite $(\sim-0.3 \mathrm{~V})$. Moreover, at a given applied potential, the ORR current of the $\mathrm{CN}_{x}$ /graphene composite is obviously stronger than that of the PPy/rGO composite. These results indicate that pyridinic and graphitic nitrogen rather than pyrrolic nitrogen contributes significantly to the ORR catalytic activity [27,28]. The activity of the carbon-nitrogen metal-free materials is synergistically deter- mined by nitrogen content, the chemical state of nitrogen and the electrical conductivity. Although the $\mathrm{CN}_{x} / \mathrm{G}-600$ catalyst has a higher amount of total and pyridinic nitrogen than the $\mathrm{CN}_{x} / \mathrm{G}-800$ catalyst, the latter has a smaller resistance, i.e., higher conductivity than the former according to the electrochemical impedance measurements (Figure S2). Therefore, $\mathrm{CN}_{x} / \mathrm{G}-600$ and $\mathrm{CN}_{x} / \mathrm{G}-800$ have similar activity. The transferred electron number $(n)$ per oxygen molecule involved in the ORR was calculated using a RRDE measurement (Figure 5(b)) and $n=4 I_{\text {disk }} /\left(I_{\text {disk }}+I_{\text {ring }} / N\right)$ [15], where $I_{\text {disk }}$ and $I_{\text {ring }}$ are the faradaic disk current and the faradaic ring current while $N=0.26$ is the collection efficiency. Here $n$ was calculated at a polarized potential of $-0.5 \mathrm{~V}$, which is 3.03 for $\mathrm{CN}_{x} / \mathrm{G}-600$ and 3.07 for $\mathrm{CN}_{x} / \mathrm{G}-800$, and this is higher than that of the $\mathrm{CN}_{x}$ /graphene composite prepared by 

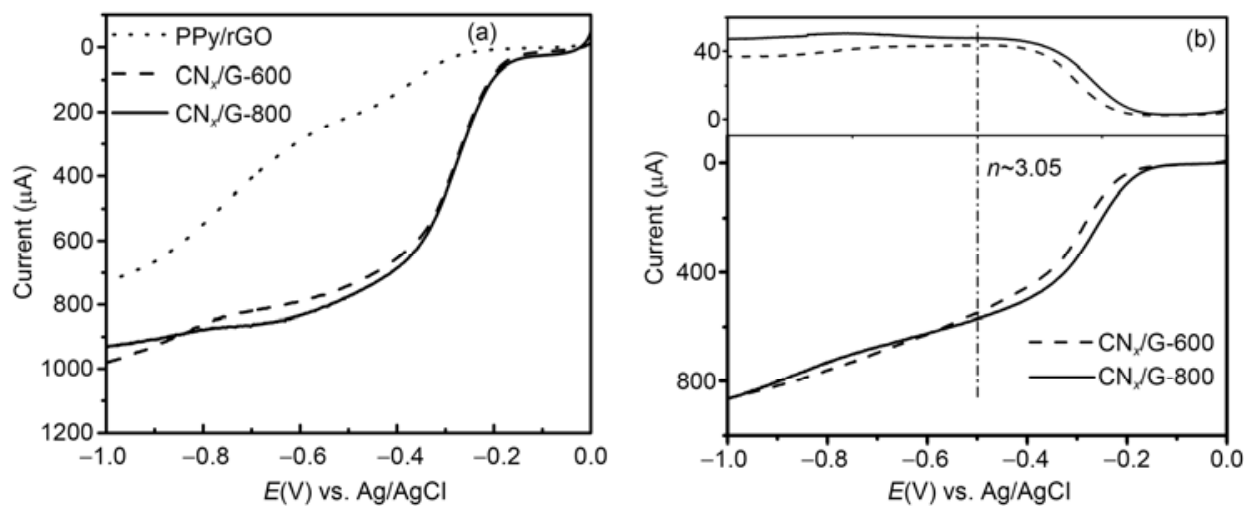

Figure 5 RED (a) and RRED (b) voltammetries measured in an $\mathrm{O}_{2}$-saturated $0.1 \mathrm{~mol} / \mathrm{L} \mathrm{KOH}$ electrolyte with a rotation speed of $2000 \mathrm{r} / \mathrm{min}$ and a scan rate of $10 \mathrm{mV} \mathrm{s}^{-1}$. In the RRDE tests, the Pt ring electrode was polarized at $0.5 \mathrm{~V}$.
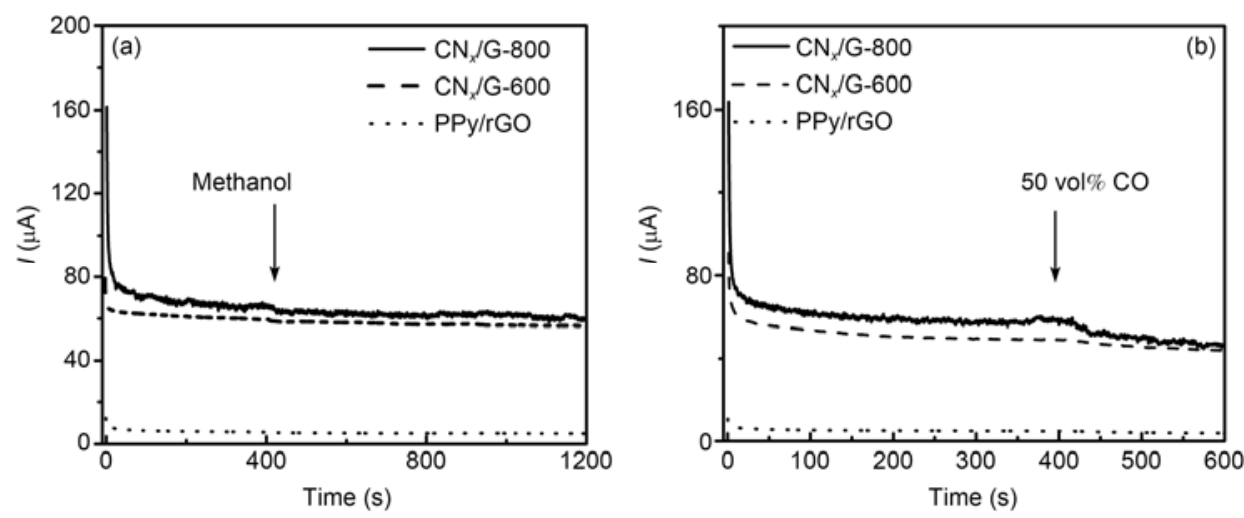

Figure 6 The $i-t$ chronoamperometric responses for PPy/rGO, $\mathrm{CN}_{x} / \mathrm{G}-600$ and $\mathrm{CN}_{x} / \mathrm{G}-800$. (a) Methanol crossover tests after the introduction of $0.1 \mathrm{~mL}$ methanol to the electrolyte at $400 \mathrm{~s}$. (b) $\mathrm{CO}$ poisoning tests by introducing additional $\mathrm{CO}$ at the same $\mathrm{O}_{2}$ flow rate into the electrolyte at $400 \mathrm{~s}$.

the polymerization of melamine $(n=2.5-2.7)$ [29]. This may be caused by the good graphitization that results from the higher calcination temperature used.

Another prominent advantage of the metal-free catalyst for the ORR is its immunity to methanol crossover and CO poisoning. Chronoamperometric responses to the methanol or $\mathrm{CO}$ that were introduced into the $\mathrm{O}_{2}$-saturated electrolyte were carried out for the PPy/rGO, $\mathrm{CN}_{x} / \mathrm{G}-600$ and $\mathrm{CN}_{x} / \mathrm{G}$ 800 catalysts, as shown in Figure 6. After the addition of $0.1 \mathrm{~mL}$ methanol at $400 \mathrm{~s}$, the oxygen reduction current for all the catalysts did not show an obvious change. When $50 \mathrm{vol} \%$ CO was injected at $400 \mathrm{~s}$, a slight decrease in the current was observed, which may be caused by the decreased partial pressure of $\mathrm{O}_{2}$ (Henry's law). These results indicate that the $\mathrm{CN}_{x}$ /graphene composite has high stability and durability towards methanol crossover and $\mathrm{CO}$ poisoning.

\section{Conclusion}

In summary, $\mathrm{rGO}$ was prepared by hydrothermal treatment and used instead of GO as a substrate to immobilize PPy. In contrast to the agglomeration of the dried PPy/GO compo- site, the dried PPy/rGO composite is a loose powder and can easily be dispersed in aqueous media. After simple calcination at $600-800^{\circ} \mathrm{C}$, sheet-like $\mathrm{CN}_{x}$ /graphene with a nitrogen content of 9.8 at $\%-12.5$ at $\%$ was obtained. The as-prepared $\mathrm{CN}_{x} /$ graphene composite has an inherent catalytic activity for the ORR and high stability and immunity towards methanol crossover and $\mathrm{CO}$ poisoning. The $\mathrm{CN}_{x} /$ graphene composite prepared in this way is a new metal-free electrocatalyst for the ORR.

This work was supported by the National Basic Research Program of China (2009CB930600), the National Natural Science Foundation of China (20833002, 20903057, 20905038, 20974046), the Research Fund for the Doctoral Program of Higher Education of China (20093223120002), the Natural Science Foundation of Jiangsu Province (BK2010525), the Foundation of Jiangsu Educational Committee (09KJB150007, 08KJB150011) and the Scientific Research Foundation of Nanjing University of Posts and Telecommunications (NY208046).

1 Wee J H. Applications of proton exchange membrane fuel cell systems. Renew Sust Energy Rev, 2007, 11: 1720-1738

2 Kamarudina S K, Achmada F, Daud W R W. Overview on the application of direct methanol fuel cell (DMFC) for portable electronic devices. Int J Hydrogen Energy, 2009, 34: 6902-6916

3 Gasteiger H A, Markovic N M. Just a dream-or future reality? 
Science, 2009, 324: 48-49

4 Rajesh B, Piotr Z. A class of non-precious metal composite catalysts for fuel cells. Nature, 2006, 443: 63-66

5 Bjorn W J, Orawan W J, Maria F, et al. High rates of oxygen reduction over a vapor phase-polymerized PEDOT electrode. Science, 2008, 321: 671-674

6 Ziegelbauer J M, Gullá A F, O'Laoire C, et al. Chalcogenide electrocatalysts for oxygen-depolarized aqueous hydrochloric acid electrolysis. Electrochim Acta, 2007, 52: 6282-6294

7 Bezerra C W B, Zhang L, Lee K C, et al. A review of $\mathrm{Fe}-\mathrm{N} / \mathrm{C}$ and $\mathrm{Co}-\mathrm{N} / \mathrm{C}$ catalysts for the oxygen reduction reaction. Electrochim Acta, 2008, 53: 4937-4951

8 Chen J, Zhang W M, Officer D, et al. A readily-prepared, convergent, oxygen reduction electrocatalyst. Chem Commun, 2007, 3353-3355

9 Lee K C, Zhang L, Lui H S, et al. Oxygen reduction reaction (ORR) catalyzed by carbon-supported cobalt polypyrrole (Co-PPy/C) electrocatalysts. Electrochim Acta, 2009, 54: 4704-4711

10 Lyth S M, Nabae Y, Moriya S, et al. Carbon nitride as a non precious catalyst for electrochemical oxygen reduction. J Phys Chem C, 2009, 113: 20148-20151

11 Biddinger E J, Deak D V, Ozkan U S. Nitrogen-containing carbon nanostructures as oxygen-reduction catalysts. Top Catal, 2009, 52: $1566-1574$

12 Noto V D, Negro E. Development of nano-electrocatalysts based on carbon nitride supports for the ORR processes in PEM fuel cells. Electrochim Acta, 2010, 55: 7564-7574

13 Liu G, Li X G, Ganesan P, et al. Development of non-precious metal oxygen-reduction catalysts for PEM fuel cells based on N-doped ordered porous carbon. Appl Catal B-Environ, 2009, 93: 156-165

14 Gong K P, Du F, Xia Z H, et al. Nitrogen-doped carbon nanotube arrays with high electrocatalytic activity for oxygen reduction. Science, 2009, 323: 760-764

15 Tang Y F, Allen B L, Kauffman D R, et al. Electrocatalytic activity of nitrogen-doped carbon nanotube cups. J Am Chem Soc, 2009, 131: 13200-13201

16 Zhu C, Higgins D, Tao H S, et al. Highly active nitrogen-doped carbon nanotubes for oxygen reduction reaction in fuel cell applications. J Phys Chem C, 2009, 113: 21008-21013

17 Chen Z, Higgins D, Chen Z W, et al. Nitrogen doped carbon nanotubes and their impact on the oxygen reduction reaction in fuel cells. Carbon, 2010, 48: 3057-3065

18 Xiong W, Du F, Liu Y, et al. 3-D carbon nanotube structures used as high performance catalyst for oxygen reduction reaction. J Am Chem Soc, 2010, 132: 15839-15841

19 Yu D S, Zhang Q, Dai L M. Highly efficient metal-free growth of nitrogen-doped single-walled carbon nanotubes on plasma-etched substrates for oxygen reduction. J Am Chem Soc, 2010, 132: 15127-15129

20 Lefèvre M, Proietti E, Jaouen F, et al. Iron-based catalysts with improved oxygen reduction activity in polymer electrolyte fuel cells. Science, 2009, 324: 71-74
21 Qin H Y, Liu Z X, Ye L Q, et al. The use of polypyrrole modified carbon-supported cobalt hydroxide as cathode and anode catalysts for the direct borohydride fuel cell. J Power Sources, 2009, 192: 385-390

22 Qin H Y, Lao S J, Liu Z X, et al. Effects of heat treatment on the structure, morphology and electrocatalytic activity of cobalt hydroxide electrocatalyst. Int J Hydrogen Energy, 2010, 35: 1872-1878

23 Yoo E J, Okata T, Akita T, et al. Enhanced electrocatalytic activity of Pt subnanoclusters on graphene nanosheet surface. Nano Lett, 2009, 9: 2255-2259

24 Seger B, Kamat P V. Electrocatalytically active graphene-platinum nanocomposites. Role of 2-D carbon support in PEM fuel cells. J Phys Chem C, 2009, 113: 7990-7995

25 Qu L T, Liu Y, Baek J B, et al. Nitrogen-doped graphene as efficient metal-free electrocatalyst for oxygen reduction in fuel cells. ACS Nano, 2010, 4: 1321-1326

26 Shao Y Y, Zhang S, Engelhard M H, et al. Nitrogen-doped graphene and its electrochemical applications. J Mater Chem, 2010, 20: 7491-7496

27 Jafri R I, Rajalakshmi N, Ramaprabhu S. Nitrogen doped graphene nanoplatelets as catalyst support for oxygen reduction reaction in proton exchange membrane fuel cell. J Mater Chem, 2010, 20: 7114-7117

28 Lee K R, Lee K U, Lee J W, et al. Electrochemical oxygen reduction on nitrogen doped graphene sheets in acid media. Electrochem Commun, 2010, 12: 1052-1055

29 Sun Y Q, Li C, Xu Y X, et al. Chemically converted graphene as substrate for immobilizing and enhancing the activity of a polymericcatalyst. Chem Commun, 2010, 46: 4740-4742

30 Wei D C, Liu Y Q, Wang Y, et al. Synthesis of N-doped graphene by chemical vapor deposition and its electrical properties. Nano Lett, 2009, 9: 1752-1758

31 Li X L, Wang H L, Robinson J T, et al. Simultaneous nitrogen doping and reduction of graphene oxide. J Am Chem Soc, 2009, 131: 15939-15944

32 Zhang K, Zhang L L, Zhao X S, et al. Graphene/polyaniline nanofiber composites as supercapacitor. Chem Mater, 2010, 22: 1392-1401

33 Cote L J, Kim F, Huang J X. Langmuir Blodgett assembly of graphite oxide single layers. J Am Chem Soc, 2009, 131: 1043-1049

34 Jiang X, Ma Y W, Li J J, et al. Self-assembly of reduced graphene oxide into three-dimensional architecture by divalent ion linkage. J Phys Chem C, 2010, 114: 22462-22465

35 Guo H L, Wang X F, Qian Q Y, et al. A green approach to the synthesis of graphene nanosheets. ACS Nano, 2009, 9: 2653-2659

36 Ma Y W, Jiang S J, Jian G Q, et al. $\mathrm{CN}_{x}$ nanofibers converted from polypyrrole nanowires as platinum support for methanol oxidation. Energy Environ Sci, 2009, 2: 224-229

37 Zhang X T, Zhang J, Song W H, et al. Controllable synthesis of conducting polypyrrole nanostructures. J Phys Chem B, 2006, 110: 1158-1165

38 Kudin K N, Ozbas B, Schniepp H C, et al. Raman spectra of graphite oxide and functionalized graphene sheets. Nano Lett, 2008, 8: 36-41

39 Choi $\mathrm{H} \mathrm{C}$, Song $\mathrm{H}$ J, Jung $\mathrm{H}$, et al. Release of $\mathrm{N}_{2}$ from the carbon nanotubes via high-temperature annealing. J Phys Chem B, 2005, 109: $1683-1688$

Open Access This article is distributed under the terms of the Creative Commons Attribution License which permits any use, distribution, and reproduction in any medium, provided the original author(s) and source are credited.

\section{Supporting Information}

SI 1 Thermogravimetry measurement of PPy/rGO powder

SI 2 Electrochemical impedance spectroscopy of $\mathrm{CN}_{x} /$ graphene composite

The supporting information is available online at csb.scichina.com and www.springerlink.com. The supporting materials are published as submitted, without typesetting or editing. The responsibility for scientific accuracy and content remains entirely with the authors. 